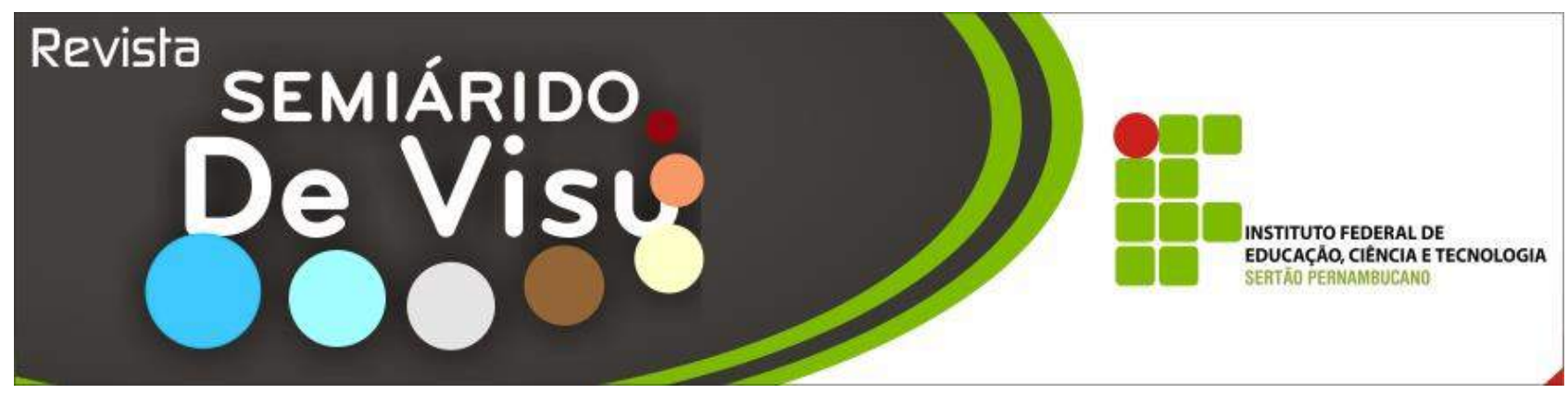

\title{
Ecodinâmica e vulnerabilidade ambiental: Ilha do Fogo em Juazeiro/BA
}

\author{
Indiane Gomes de Carvalho' ${ }^{1}$, Clecia Simone Gonçalves Rosa Pacheco² \\ ${ }^{\mathbf{1}}$ Instituto Federal de Educação Ciência e Tecnologia do Sertão Pernambucano - Campus Petrolina \\ BR 407, Km 08 - Jardim São Paulo - Petrolina/PE/Brasil - CEP 56.314-520 - Telefone: (87) 2101 - 4300 - E-mail: \\ didiufdj@hotmail.com; \\ ${ }^{2}$ Instituto Federal de Educação Ciência e Tecnologia do Sertão Pernambucano - Campus Petrolina \\ BR 407, Km 08 - Jardim São Paulo - Petrolina/PE/Brasil - CEP 56.314-520 - Telefone: (87) 2101 - 4300 - E-mail: \\ clecia.pacheco@gmail.com;
}

\begin{abstract}
RESUMO: O presente artigo aborda sobre a paisagem fluvial da Ilha do Fogo - rio São Francisco - Juazeiro/BA, sua ecodinâmica e vulnerabilidade ambiental. A referida pesquisa corresponde ao relatório final do projeto intitulado: Análise ecodinâmica da paisagem fluvial da ilha do fogo: a importância geossistêmica dessa área para as cidades de Juazeiro/BA e Petrolina/PE, fazendo parte do Programa Institucional de Bolsas de Iniciação Científica (PIBIC 2013-2014). Objetivouse nesse projeto, traçar uma análise ecodinâmica da área descrita, avaliando em microescala, o grau de vulnerabilidade deste geossistema, bem como, a intensidade dos processos erosivos do solo e os impactos socioambientais relacionados aos demais componentes do meio físico-biótico, além das formas de ocupação e uso do local. A metodologia utilizada fundamentou-se na abordagem ecodinâmica proposta por Tricart (1977) e, no método GTP (Geossistema - Território Paisagem) preconizado por Bertrand (2007). Mediante os resultados encontrados, pode-se afirmar que é imprescindível monitorar os processos erosivos, conservar a mata ciliar e implementar políticas de gestão do uso e ocupação da área, baseadas nos preceitos da sustentabilidade socioambiental.
\end{abstract}

Palavras-chave: Paisagem fluvial, Geossistêmica, Impacto socioambientais

\section{Ecodynamics and environmental vulnerability: Fogo Island in Juazeiro / BA}

\begin{abstract}
This article discusses on the river landscape of Fogo Island - river Sao Francisco - Juazeiro / BA, its ecodynamics and environmental vulnerability. That corresponds to the final research project report titled: Analysis of river landscape ecodynamics Ilha do Fogo: geosystemic the importance of this area for the cities of Juazeiro/BA and Petrolina/PE, part of the Scholarship Program for Scientific Initiation (PIBIC 2013-2014). The objective of this project, draw a ecodynamics analysis of the area described, assessing microscale, the degree of vulnerability of this geosystem, as well as the intensity of soil erosion and environmental impacts related to the other components of the physical and biotic environment, as well forms of land use and location. The methodology is based on the approach proposed by ecodynamics Tricart (1977) and the GTP method (Geosystem - Planning - Landscape) advocated by Bertrand (2007). Through the results, it can be stated that it is essential to monitor erosion, conserve riparian and implement policies for managing the use and occupation of the area, based on the principles of environmental sustainability.
\end{abstract}

Keywords: River landscape, Geosystemic, Environmental impact 
(CARVALHO; PACHECO, 2016)

\section{Introdução}

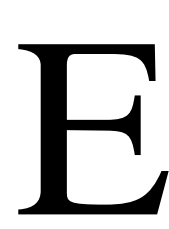

studos ambientais acerca da região semiárida são de grande relevância, já que tomam a paisagem como o sistema geral onde se processam a interação do potencial ecológico, a exploração biológica e a ação humana e o consequente grau de desestabilização dos ecossistemas de forma integrada ao meio físico-geográfico. Estudos dessa natureza vêm contribuindo para a atenuação dos processos de degradação dos recursos naturais, principalmente da erosão dos solos, do desmatamento e assoreamento das áreas fluviais.

No desdobrar da história, os rios têm sido aproveitados como vias de adentramento para o interior e facilitador da ascensão de aglomerado urbano e áreas cultivadas, uma vez que a água é um recurso crucial para a sobrevivência humana. Neste sentido, os rios espelham, de maneira indireta, as condições naturais e as atividades humanas desenvolvidas na bacia hidrográfica, sofrendo, em função de escala e intensidade de mudanças nesses dois elementos, alterações e efeitos e/ou impactos no comportamento da descarga, carga sólida e dissolvida, e poluição das águas (Cunha, 2008). $\mathrm{Na}$ maioria das vezes, os fatos naturais, tais como, topografia, geologia, solos, clima e vegetação, podem encetar os desequilíbrios que serão intensificados pelas atividades antropogênicas na bacia hidrográfica, especialmente pelo manejo inadequado dos solos urbano e rural com a substituição das matas ciliares por terras cultivadas e o avanço do processo de urbanização.

A decomposição dos solos em bacias hidrográficas está atrelada ao desequilíbrio entre a morfologia das encostas e o fluxo de água (Guerra \& Mendonça, 2004). Na bacia hidrográfica do rio São Francisco, onde está inserida a microárea de estudo, os processos erosivos e de assoreamento são relacionados à dinâmica hidrológica, sobretudo pela morfologia dos canais, e oscilação dos fluxos, como também pela estrutura edafoclimática, o estado da cobertura vegetal, e de forma integrada as formas de uso e ocupação do solo pela população local.

Mediante tais premissas, o presente artigo se propõe a discutir a avaliação realizada em microescala, baseado em suportes geomorfológicos, acerca da intensidade dos processos erosivos do solo e dos impactos socioambientais relacionados aos demais componentes do meio físico-biótico e as formas de ocupação e uso da Ilha do Fogo Juazeiro/BA, situada à jusante esquerda do rio supracitado.

Para o desenvolvimento desta pesquisa descritiva houve a necessidade de uma busca prévia na literatura acerca das temáticas tratadas para uma melhor compreensão e fundamentação teórica, por meio de leitura, discussões/comparações entre ideias de vários autores. Em seguida realizou-se a pesquisa de campo, onde fez-se uma análise sistemática de quatro parâmetros considerados cruciais à investigação: estrutura superficial da paisagem, uso do solo, vegetação e processos superficiais. Para cada um dos parâmetros citados, procurouse categorizar baseando-se na abordagem de Tricart (1977) e nas concepções de Bertrand (2007).

Tricart propôs uma metodologia para classificação do ambiente com base no estudo da dinâmica dos ecótopos, a qual denominou de ecodinâmica. A premissa básica é que a dinâmica do ambiente onde se incluem os ecossistemas é tão importante para a conservação e o desenvolvimento dos recursos ecológicos, quanto para a dinâmica das próprias biocenoses. Dessa maneira, "o conceito de unidade ecodinâmicas é integrado no conceito de ecossistema. Baseia-se no instrumento lógico de sistema, e enfoca as relações mutuas entre os diversos componentes da dinâmica e os fluxos de energia/ matéria no meio ambiente." (Tricart, 1977, pag. 31).

Já a aplicabilidade do sistema GTP como metodologia é reaproximar estes três conceitos para analisar como funciona um determinado espaço geográfico em sua totalidade. Sendo assim, essencialmente, se trata 
de compreender as interações entre elementos constitutivos diferentes para analisar a dialética existente entre a paisagem, o território e o geossistema. A visualização das relações entre os elementos da paisagem deve levar o pesquisador a compreender a dinâmica da área estudada e como ela dialoga com as áreas do seu entorno.

Portanto, esta pesquisa pretendeu contemplar a vivência, na prática, de conteúdos da componente curricular - Geografia - dando ênfase a Geografia Física, a fim de fomentar na comunidade escolar releituras para reconstrução e valorização das paisagens naturais locais, destacando a relevância dessas paisagens atuais para a compreensão do comportamento de climas e hidrografias pretéritas. De acordo com Christofoletti (1999), a Geografia Física, como subárea da ciência geográfica, ocupa-se com o estudo da organização espacial dos sistemas ambientais físicos, onde estão incluídos os geossistemas.

\section{Material e métodos}

A área da pesquisa encontra-se em meio ao rio São Francisco, no trecho compreendido entre as cidades de Juazeiro/BA e Petrolina/PE, situada nas coordenadas geográficas $09^{\circ} 23,5^{\prime} 42^{\prime \prime} \mathrm{S} 40^{\circ} 30^{\prime} 18^{\prime \prime W}$. A Ilha do Fogo está localizada no centro da ponte Presidente Eurico Gaspar Dutra, marcando a divisa entre os Estados da Bahia (Juazeiro) e Pernambuco (Petrolina), possuindo uma área praiana com terreno acidentado, formado por uma rocha única, de aproximadamente $20 \mathrm{~m}$ de altura, onde está fixado um cruzeiro, conforme a figura 1.

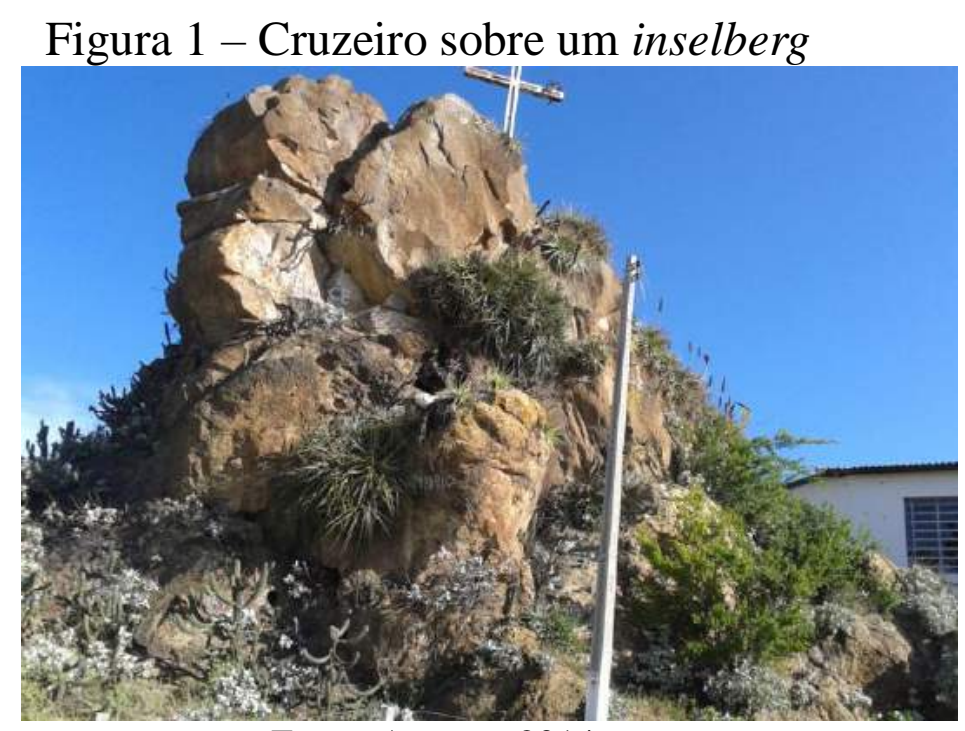

Fonte: Autoras, 2014.

Com base nos objetivos a referida pesquisa apresenta-se como descritiva, que visa observar, registrar, analisar e correlacionar fenômenos ou fatos, sem interferir no ambiente analisado, sendo o tipo de pesquisa mais utilizado nas ciências sociais. (Vieira, 2002; Malhotra, 2001). No entanto, quanto aos fins, a mesma é do tipo exploratória, porque visa fazer um levantamento bibliográfico e análise in loco, além de proporcionar maior familiaridade com o problema, constituindo-se assim, numa pesquisa exploratória e descritiva.
Partindo destes pressupostos e visando atender aos objetivos propostos, traçou-se o seguinte caminho nesta pesquisa: inicialmente se fez leituras a teóricos que abordam acerca da abordagem ecodinâmica e do método GTP, bem como, de autores que versam sobre os processos que dão origem a ilhas fluviais, a partir da escolha de artigos científicos publicados no Scielo e de alguns livros de autores renomados que tratam destas questões. Após a leitura fez-se fichamento de pontos mais relevantes da leitura e uma breve discussão entre coordenador e orientando para 
clarificação de conceitos fundamentais à pesquisa. Após leituras, fichamento e discussão, partiu-se para a pesquisa em campo. A pesquisa em campo ocorreu em três visitações ao local buscando traçar uma análise sistemática de quatro parâmetros considerados cruciais: estrutura superficial da paisagem, uso do solo, vegetação e processos superficiais. Para cada um dos parâmetros citados, corresponde um nível categórico de equilíbrio, a fim de mensurar a intensidade da vulnerabilidade e dos processos desencadeados na área. Após a busca de dados, in loco, estes foram analisados e discutidos, onde os resultados obtidos indicaram o nível de estabilidade da área foco da pesquisa.

Para análise e discussão da pesquisa utilizaram-se os dados obtidos em campo, cruzando-os com as afirmações dos teóricos elencados como embasamento para tal pesquisa. Feito isto, chegou-se à conclusão da situação real dessa paisagem fluvial, podendo assim traçar o perfil da mesma e o seu grau de estabilidade, sendo que esta é de grande relevância, pois se trata de um dos cartões postais naturais do Vale do Submédio São Francisco.

\section{Resultados e discussões}

Conforme a metodologia adotada na pesquisa, a investigação da área em tese ocorreu por meio da análise ecodinâmica da paisagem, de acordo com a seguinte categorização de Tricart (1977): meios estáveis $^{1}$, meios intergrades ${ }^{2}$ e meios fortemente instáveis ${ }^{3}$. Tal método foi escolhido por entender que a ecodinâmica baseia-se no estudo dinâmico dos ecótopos. A dinâmica do

\footnotetext{
${ }^{1}$ São caracterizados pelo predomínio da pedogênese sobre os processos erosivos. Neste meio, a cobertura vegetal atua impedindo o desenvolvimento dos processos mecânicos capazes de gerar dissecação. Tricart denomina este fenômeno como fitoestabilidade, levando em consideração o importante papel da vegetação na morfodinâmica (CASSETI, 1991).

${ }^{2}$ Caracteriza-se pelo predomínio é da morfogênese. Este fenômeno pode resultar de flutuações climáticas e efeitos tectônicos ao longo do tempo geológico, ou de
}

meio ambiente e dos ecossistemas é muito relevante para a conservação e o desenvolvimento dos recursos ecológicos, onde ambos os aspectos desta dinâmica ecossistêmica estão relacionados entre si. Uma unidade ecodinâmica na óptica de Tricart (1977) se caracteriza por certa dinâmica do meio ambiente que tem repercussões mais ou menos imperiosa sobre a biocenose.

Sendo assim, é possível afirmar que a natureza está sempre em processo de mutação e evolução, onde os estudiosos do meio ambiente não podem limitar-se as descrições fisiográficas, tendo sempre que revolucionar os estudos da organização do espaço, pois é determinante ter uma ação que se insere na dinâmica natural, para corrigir aspectos desfavoráveis na exploração dos recursos ecológicos.

Em geral, dissecações moderadas afetam essencialmente regiões tectonicamente calmas desde longo tempo, enquanto as áreas solevadas mostram tendências nítidas à incisão dos cursos d'água que acentuam os declives das encostas e aceleram a evolução. É a estabilidade que determina o tempo a partir da pedogênese pode se exercer, ou seja, a idade dos solos, que influencia no grau de evolução dos mesmos e caracteriza tanto morfologicamente quanto analiticamente.

Desta maneira, o andamento do processo do sistema morfogenéticos tem muitas interferências, na maioria das regiões tem oscilações climáticas que são suficientes para engendrar modificações fisionômicas na cobertura vegetal que influencia no sistema. Segundo Tricart (1977, p. 39) "os solos, notadamente frágeis por sua débil espessura e coesão, são longamente conservados, ainda que raramente in torum. [...] Encontram-se solos que

intervenções humanas na escala de tempo histórica. Para estes meios a pedogênese torna-se nula ou incipiente (CASSETI, 1991).

3 Segundo Casseti (1991), como um meio transicional. Refere-se ao estado de modificação do sistema fitoestável antes de ultrapassar o limiar de recuperação, proporcionando a possibilidade de restauração ou de transformar-se em um meio fortemente instável permanentemente. 
foram trucados, depois enterrados, tendo ocorrido os dois fenômenos durante um período de instabilidade geodinâmica".

Assim sendo, alguns trechos da área pesquisada, ainda permanecem estáveis (figura
2) com condições de conservação. Essas áreas são raras, por isso deve-se manter uma cobertura vegetal densa com efeitos equivalentes à cobertura natural, para uma conservação dessa variedade estável.

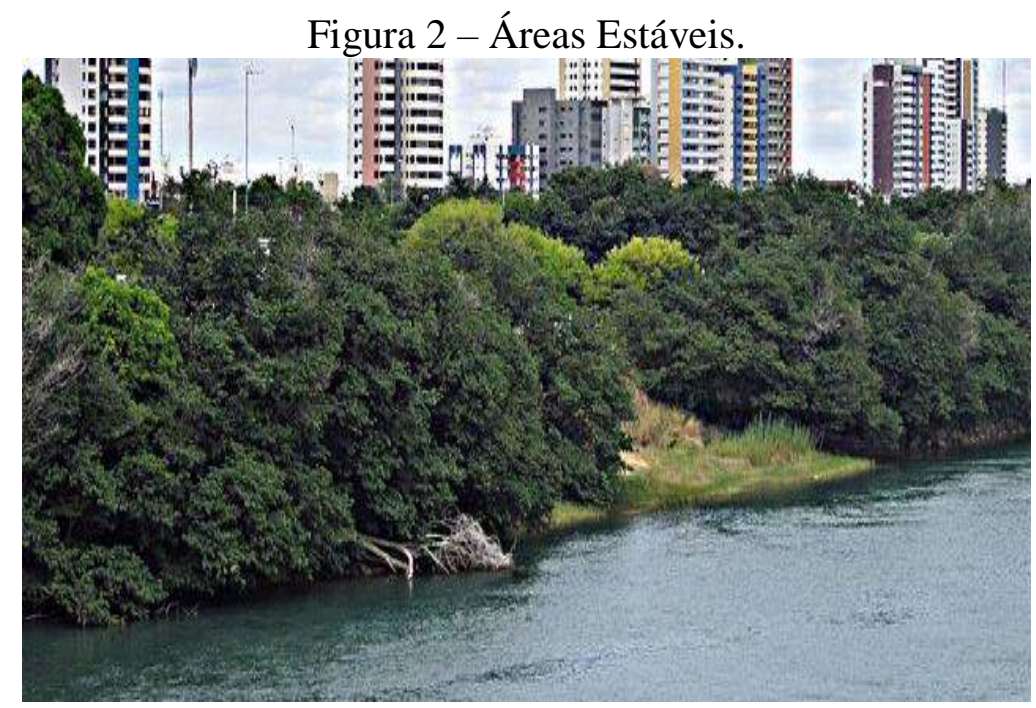

Fonte: Autoras, 2014.

A figura 2 demonstra uma área na borda da ilha margeada pelo rio São Francisco, com densa cobertura vegetal, considerada como estável baseada nas premissas de Tricart (1977). No entanto, em caso de retirada da vegetação ciliar para facilitar visitas turísticas, ou acesso de banhistas e pescadores, entre outros, em ilhas fluviais vem causando problemas, tornando-se crucial fazer um trabalho de levantamento de dados, ordenamento e manejo do território, tratamento dos cursos d'água, remodelação agrícola das bacias vertentes com a conservação das florestas, entre outros aspectos indispensáveis à gestão de áreas fluviogeográficas.

Estes problemas vêm agravando a cada dia em muitas partes do país, principalmente nas cidades onde ocorrem enchentes que deixam bairros totalmente submersos pela a água pluvial e fluvial, principalmente aqueles próximos de cursos de rios, denominados ribeirinhos. Entretanto, já é comum encontramos no entorno da ilha pesquisada, áreas consideradas como intergrades, isto é, em estágio de transição, entre o estável e instável, conforme a figura 3.

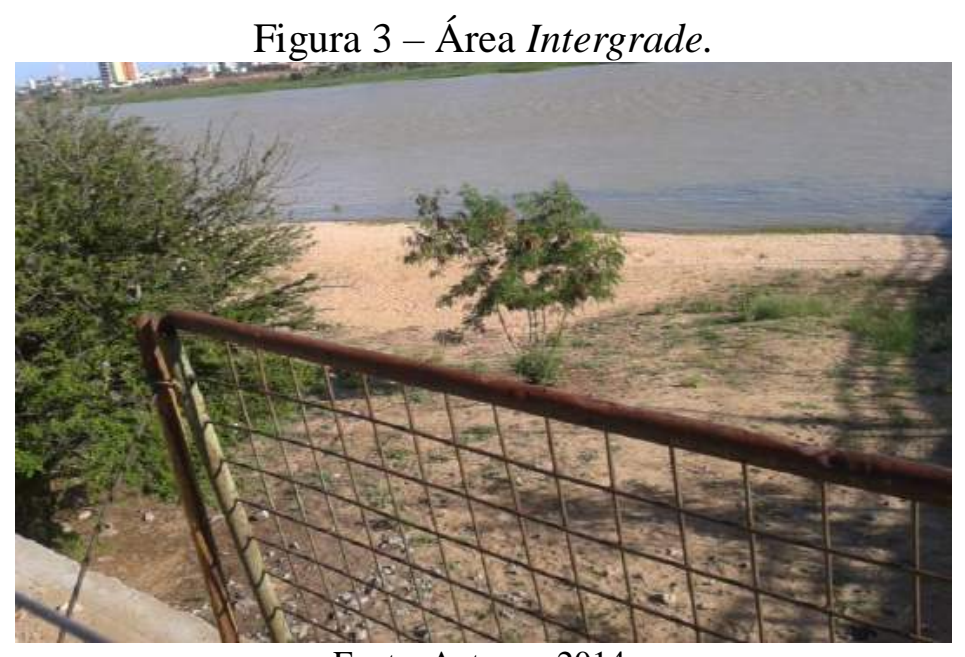

Fonte: Autoras, 2014. 
A figura 3 demonstra um trecho da ilha onde não há vegetação ciliar na margem do rio $\mathrm{e}$, as areias ficam inconsolidadas pelo avanço e recuo natural das águas do rio São Francisco, seja pelo aumento da vazão (quando Sobradinho libera maior fluxo de água abrindo suas comportas), seja pelo atracamentos dos barcos ou lanchas que cruzam diariamente a área.

No que concerne aos meios fortemente instáveis, nestes a morfogênese ${ }^{4}$ é fator determinante no sistema natural e os outros elementos estão subordinados. A geodinâmica ${ }^{5}$ interna intervém em vários casos. "As deformações tectônicas comandam todos os processos nos quais intervém a gravidade, favorecendo a dissecação das áreas elevadas, com incisão dos cursos d'água e crescimento correlato dos declives das encostas" (Tricart, 1977, p. 53). Além disso, os processos antropogênicos são os maiores atenuadores dos impactos ambientais em áreas fluviais.

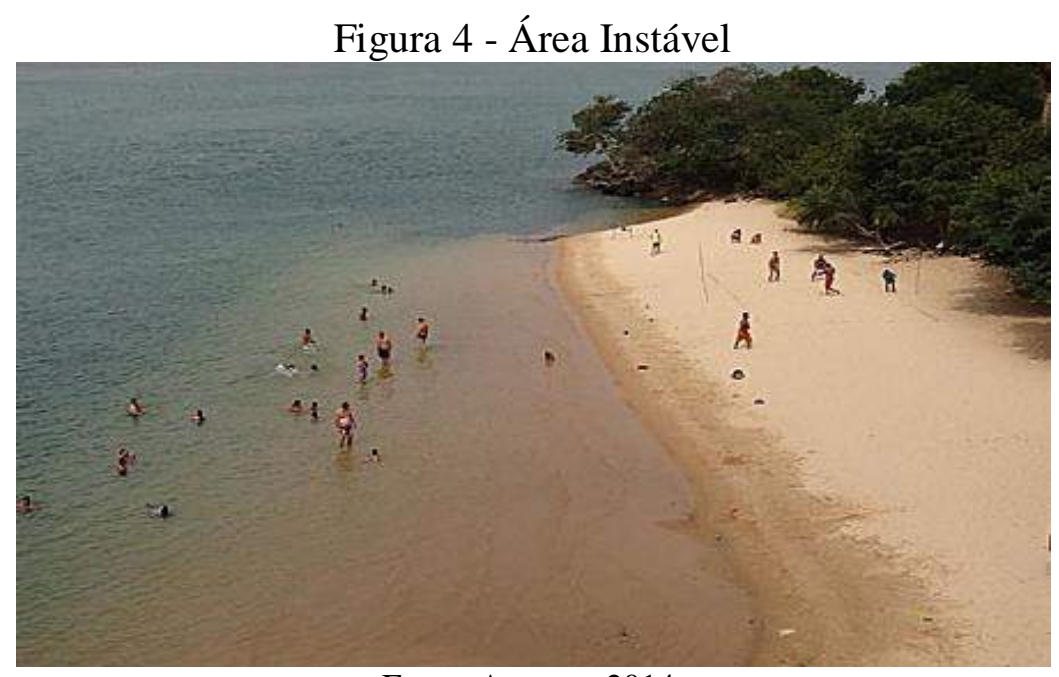

Fonte: Autoras, 2014.

Observa-se na figura 4 que a faixa praial da ilha do fogo, é aproveitada para inúmeras atividades de lazer e desportiva, que vão desde o mergulho nas águas, o futebol de areia, atividades fittines (academias), caminhadas, hidroginástica, treinamentos do Corpo de Bombeiro local e do Exército brasileiro (instalado na ilha) entre tantos outros aspectos.

Todo esse contato entre homem-natureza deve ser feito de maneira equilibrada e sustentável, embora, quem visita o local percebe que ao encerrar um final de semana, geralmente há muito lixo descartado na ilha, por falta de consciência dos visitantes. Além disso, o governo local não possui uma política

\footnotetext{
${ }^{4}$ A morfodinâmica depende da interação entre o clima, a topografia, o solo, material rochoso e a cobertura vegetal. Dentre estes fatores, a vegetação possui um papel de extrema importância; o de impedir a ação dos fenômenos erosivos, sobretudo em regiões onde a mesma se apresenta bem conservada. (TRICART, 1977)
}

consolidada de fiscalização a estes locais, coibindo qualquer tipo de agressão ao meio natural e à margem do rio São Francisco.

Obviamente a ausência de cobertura vegetal tem influência indireta no clima e direta nos solos fluviais, onde os processos erosivos ficam visíveis nas áreas fluviais desnudas da vegetação natural. Nos meios morfoclimáticos de intensa ablação o regime climático pode permitir a evacuação dos produtos de meteorizacão, desde quando formados, e não dar tempo a aparecer um manto de alteritas nem com mais forte razão - a se formar uma cobertura de solos. Tem-se, assim, um regime permanente caracterizado por ausência de solos, o que é

5

A geodinâmica está na origem das mudanças geológicas da Terra quer por ação interna ou externa. Assim, é o ramo da geologia que se dedica ao estudo do conjunto de fenômenos que ocorrem na Terra e as suas consequências. (CASETTI, 1991) 
mascarado na linguagem pedológica atual com ajuda das expressões "solos minerais brutos", "regossolos", "litossolos". (Tricart, 1977).

Vários fatores devem ser levados em consideração quando se trata de ocupação do solo. O estudo da morfodinâmica auxilia na obtenção de técnicas para amortização de áreas de desmatamento por exemplo. Com base em estudos anteriores deve se subdividir desde já a área que se vai estudar em etapas. Utilizar a cobertura vegetal e os solos como índice e fundamental para uma interpretação não equivocada. As interferências antrópicas também devem ser consideradas, pois dependendo de sua amplitude pode afetar diretamente os ambientes naturais.

Para a ocupação de uma área é relevante dividir o recurso ecológico em algumas etapas, como por exemplo: observação de recursos hídricos que são de fundamental importância; sistematização das condições climáticas da região; estabelecer o grau de resistência do solo, para saber a partir daí o seu limite; fazer uma leitura da área como em um todo.

É importante que se analise claramente as possibilidades de ocupação e as melhores formas de repor as características removidas do solo, pois a gestão do território enfatiza o caráter puramente científico e técnico. A ponto de decidir com sucesso a melhor política de gestão dos territórios, principalmente em se tratando dos territórios hídricos e suas adjacências.

No entanto, para que toda essa dinâmica seja aplicável, é imprescindível que se tenha um órgão público responsável pela implementação de projetos de conservação de áreas fluviais e ao mesmo tempo, que seja também sensibilizador e fiscalizador, capaz em autonomia, de aplicar a legislação ambiental coerente de acordo com os preceitos do Conselho Nacional Meio Ambiente (CONAMA).

Portanto, na concepção de Tricart, "a maneira dinâmica de abarcar os problemas permite, por conseguinte, introduzir critérios de ordenação e gestão do território. A decisão, naturalmente, é do poder público [gestor] - que, antes de decidir, deve estar ciente das consequências de suas decisões" (Tricart, 1977, p.33).

\section{Conclusões}

O presente trabalho chegou à conclusão de que o objeto de estudo analisado ecodinamicamente possui de acordo com as premissas de Tricart (1977) a seguinte caracterização: áreas estáveis, intergrades e fortemente instáveis, tendo em vista que, o grau de vulnerabilidade presente nesse geossistema está diretamente relacionado com os impactos socioambientais relacionados aos demais componentes do meio físico-biótico. Além desses aspectos, existem mais dois agravantes, que são as formas de ocupação e o uso do local pelos atores sociais.

Sendo assim, é fulcral não apenas apontar os problemas existentes no ambiente pesquisado, mas principalmente, indicar propostas aplicáveis ou possíveis soluções para a temática abordada. Nesse sentido é implementar propostas de gestão para os três ambientes existentes na ilha - estável, intergrade e instável - mediante a seguinte sugestão:

a) Plano de Manejo e Conservação indicado para as áreas ainda estáveis. visando mantê-las estabilizadas e sem maiores agressões antropogênicas;

b) Plano de Controle e Conservação sugerido para as áreas intergrades visando assim, controlar o processo de degradação já existente e conservar o que ainda resta sem deixar aumentar os trechos em transição para o estágio instável;

c) Plano de Reflorestamento e Conservação - apontado para as áreas instáveis, tencionando o não aumento dessa instabilidade e o processo de exaustão da vegetação ciliar.

Obviamente que as propostas de conservação aqui assinaladas em forma de Planos devem ser aplicadas por órgãos competentes, responsáveis pela administração da área em foco (Ilha do Fogo), em parceria com a comunidade local, buscando por meio da sensibilização a participação ativa nesse projeto que seria um marco [se aplicado] à área fluvial em discussão. 
Portanto, espera-se tornar público tais resultados elencados à comunidade acadêmica local das cidades de Juazeiro e Petrolina e, porque não em nível nacional e internacional. Pretende-se também, motivar debates e discussão a respeito da relevância da preservação/conservação dessa paisagem natural, visando torná-la uma relíquia ou patrimônio de importância para desenvolvimento de pesquisas de cunho cientifico das geociências, neste cenário atípico do Vale do Submédio Sanfranciscano.

\section{Referências}

BERTRAND. G. Paisagem e Geografia Física Global: esboço metodológico. Caderno de Ciências da Terra. N. 13. Universidade de São Paulo. Instituto de Geografia. São Paulo: 1971.

BERTRAND, G.; BERTRAND C. Uma Geografia Transversal e de Travessias: o meio ambiente através dos territórios e das temporalidades. Maringá: Mossoni, 2007.

CASSETI, V. Ambiente e apropriação do relevo. São Paulo: Editora Contexto, 1991.
CHRISTOFOLETTI, A. Modelagem de Sistemas Ambientais. São Paulo: Edgard Blucher, 1999.

CUNHA, S. B. da. Canais Fluviais e a Questão Ambiental. In: A Questão Ambiental: diferentes abordagens. CUNHA, S. B.; GUERRA, A. J. T. (Orgs.). 4. Ed. Rio de Janeiro: Bertrand Brasil, 2008. p.219-238.

GUERRA, A. J. T.; MENDONÇA, J. K. S. Erosão dos solos e a Questão Ambiental, In: Reflexões sobre a Geografia Física no Brasil. - (orgs.) VITTE, A. C.; GUERRA, A. J. T. G. Rio de Janeiro: Ed.Bertrand Brasil, 2004, p. 225-256.

MALHOTRA, N. Pesquisa de marketing: uma orientação aplicada. 3. ed. Porto Alegre: Bookman, 2001.

TRICART, J. Ecodinâmica. Rio de Janeiro, IBGE, Diretoria Técnica, SUPREN, 1977, 91p.

VIEIRA, V. A. As tipologias, variações e características da pesquisa de Marketing. Revista da FAE, Curitiba, v. 5, n. 1, p. 61-70, jan./abr. 2002. 